\title{
Altimetry Applications to Continental Shelf Delineation under the United Nations Convention on the Law of the Sea
}

\author{
Dave Monahan \\ Canadian Hydrographic Service - Ottawa, Ontario Canada \\ University of New Brunswick - Fredericton, New Brunswick Canada
}

\section{Introduction}

The United Nations Convention on the Law of the Sea subdivides ocean space into zones that lie under either the jurisdiction of a Coastal State or of the International Seabed Authority. Although most of this subdivision can be performed by relatively straightforward measurements of horizontal distance, delineating the Juridical Continental Shelf requires complying with the complex formula prescribed in Article 76 of the Convention. Article 76 requires the vertical measurement of depth and production of an isobath, and locating the Foot of the Slope, an elusive "geomorphic" seafloor feature that may not even exist. If it does not, and if its non-existence can be proven, then "evidence to the contrary" may be used to determine the location of a substitute line. In either case, sediment thickness must be measured seawards until a specified thickness is reached. Seaward extension of the Continental Shelf is not unlimited, since two constraints are prescribed: which constraint applies varies with the seafloor to some extent, since the presence of a "ridge" prohibits the use of one of them. What constitutes a ridge is not specified in the wording of the Convention, adding a further complication. Earth scientists are thus confronted with locating the $2500 \mathrm{~m}$ isobath, finding the Foot of the Slope or establishing that it does not exist and building a case for evidence to the contrary, measuring sediment thickness and establishing the geologic nature of seafloor ridges. From this, an Outer Limit to the Continental Shelf can be established.

Modern ship-borne instruments can collect the types of data appropriate to resolving this boundary: the question, one exacerbated by the requirement to submit a claim within ten years of ratification, is whether they can collect enough of it to produce a wellfounded claim. Because ships are limited in their speed, as well as by weather and by cost, it is possible that some Coastal States will not be able to assemble appropriate amounts of data within the time limit.
Consequently any technique which offers promise of speeding up the process or contributing data must be evaluated. This paper examines the possible contribution that altimetric bathymetry may be able to make to these ends, either alone or in concert with other data sets. It does so by describing each mappable element of Article 76 and the degree to which it can be mapped by altimetry.

\section{Brief Overview of UNCLOS}

During the course of a series of meetings that lasted from 1973 to 1982, the nations of the world produced the United Nations Convention on the Law of the Sea (UNCLOS) (United Nations, 1983), a document that has been described as the result of probably the most prolonged and intense multinational negotiations in history. UNCLOS completely changed the character of the entire marine sector, and rests as the foundation on which all subsequent international and national marine legislation has been built (Miles, 1999).

Before this exercise, ocean space was essentially divided into two zones: Coastal States' sovereignty was absolute over a fringing Territorial Sea beyond which Freedom of the High Seas was held to be absolute. This was increasingly being challenged through isolated actions like the declaration of Fishing Zones. UNCLOS expanded the concept of two zones by the further subdivision of ocean space into several zones fringing continents, archipelagos and islands. Jurisdiction of Coastal States was extended, with powers being phased down through several successive zones at specified distances offshore, resulting in a much greater portion of the seafloor falling within national jurisdiction. Successively seawards, these zones are the $12 \mathrm{~nm}$ wide Territorial Sea, the $24 \mathrm{~nm}$ Contiguous Zone, the $200 \mathrm{~nm}$ Exclusive Economic Zone and the Continental Shelf, whose width is variable and has to be determined through a combination of measurement and judgement as discussed below. 
Juridical Continental Shelf

On their juridical Continental Shelves, Coastal States have the sovereign right to explore and exploit the non-living natural resources of the "sea-bed and subsoil" together with living organisms belonging to sedentary species. The size of the area requiring new bathymetric surveys to establish a United States Continental Shelf has been estimated to be approximately $860,000 \mathrm{~km}^{2}$ (Mayer et al., 2002). Although the limits of the Continental Shelves remain as yet best estimates, the value of the non-living resources on them has been estimated by Murton et al. (2000); they estimate that the US shelf alone will be worth more than $\$ 1.3$ trillion. Other Coastal States can potentially include large and valuable areas, as indicated in the sketch map in Figure 1.

Since portions of the seafloor that do not form part of a juridical Continental Shelf become the "The Area," administered by the United Nations for the "common heritage of mankind" through the International Seabed Authority, Coastal States are constrained in the Continental Shelf area over which they may have jurisdiction. Coastal States must actively delineate a shelf according to Article 76 of the Convention then submit the proposed Outer Limits to the Commission on the Limits of the Continental Shelf (CLCS) who will recommend, or not, their acceptance. Delineation consists of a number of mapping actions, discussed below, and the CLCS has issued Guidelines specifying the types, quantities and accuracies of data for each element (United Nations, 1999).

\section{Article 76 Elements}

Article 76 of UNCLOS, which combines "geography, geology, geomorphology, and jurisprudence"

\section{Table 1}

Mapping tasks for establishing a juridical Continental Shelf under Article 76 of UNCLOS and the applicability of altimetry to each.

\begin{tabular}{|c|c|}
\hline Tasks & $\begin{array}{l}\text { Applicability } \\
\text { of Altimetry }\end{array}$ \\
\hline Map baselines (shoreline points) & None \\
\hline Map 2500 m depth contour & $\begin{array}{l}\text { Applies and } \\
\text { meets the } \\
\text { standard }\end{array}$ \\
\hline Map the base of the slope & Applies \\
\hline $\begin{array}{l}\text { Map the foot of the slope } \\
\text { or prove it does not exist }\end{array}$ & Possibly \\
\hline $\begin{array}{l}\text { Optional -decide whether to use } \\
\text { the morphological Foot of the } \\
\text { Slope or "evidence to the contrary" }\end{array}$ & Possibly \\
\hline $\begin{array}{l}\text { Map sediment thickness seawards } \\
\text { of the foot of the slope }\end{array}$ & Possibly \\
\hline $\begin{array}{l}\text { Determine whether isolated } \\
\text { elevations are "natural } \\
\text { prolongations" }\end{array}$ & Possibly \\
\hline Resolve the "ridge exception" & Possibly \\
\hline $\begin{array}{l}\text { Create lines at distances of } 60 \text {, } \\
100,200 \text { and } 350 \mathrm{~nm}\end{array}$ & Not needed \\
\hline Prepare data bases for UN scrutiny & Not needed \\
\hline $\begin{array}{l}\text { Prepare a submission including } \\
\text { "charts, maps and diagrams" }\end{array}$ & Could be used \\
\hline
\end{tabular}

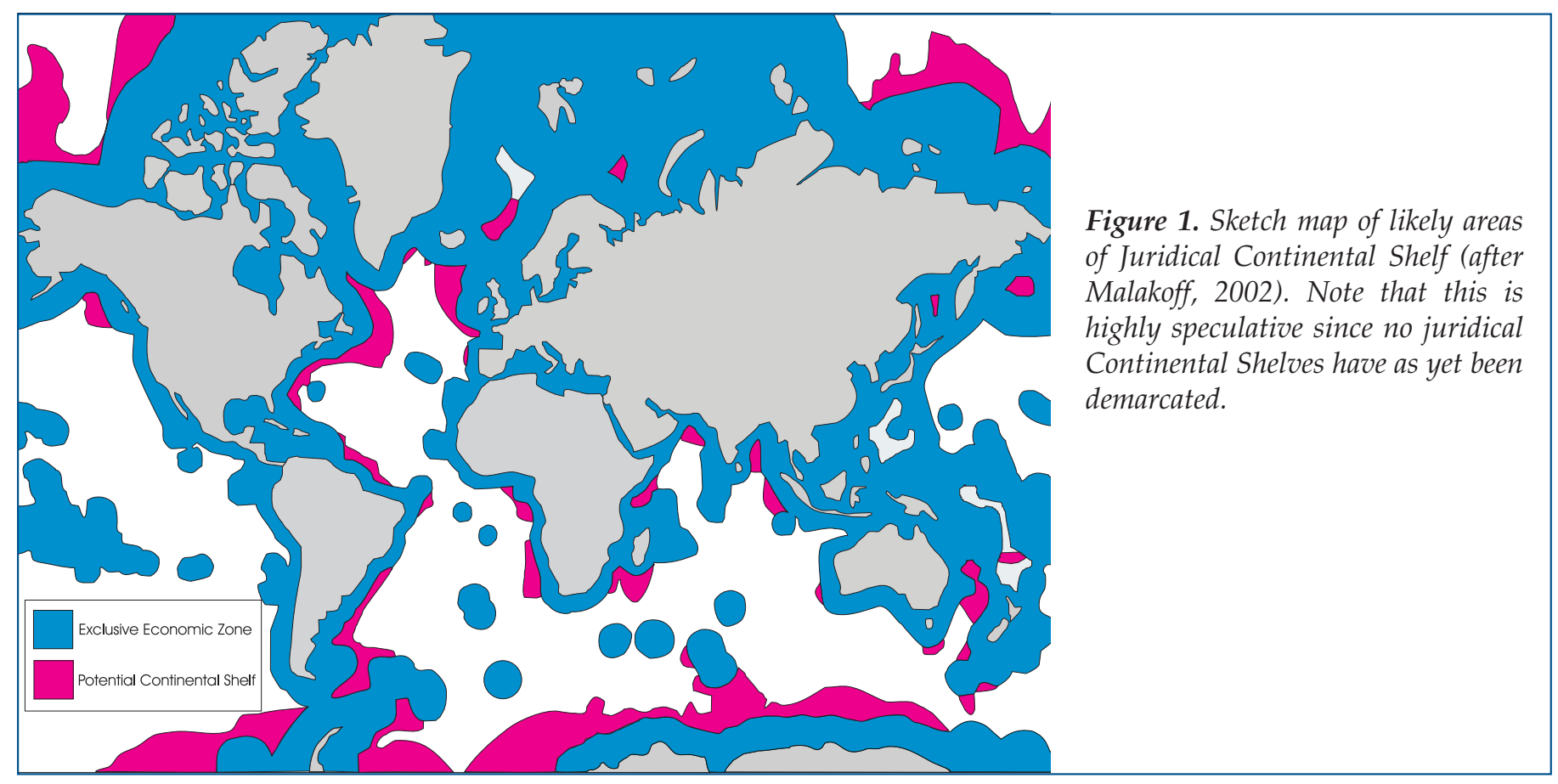



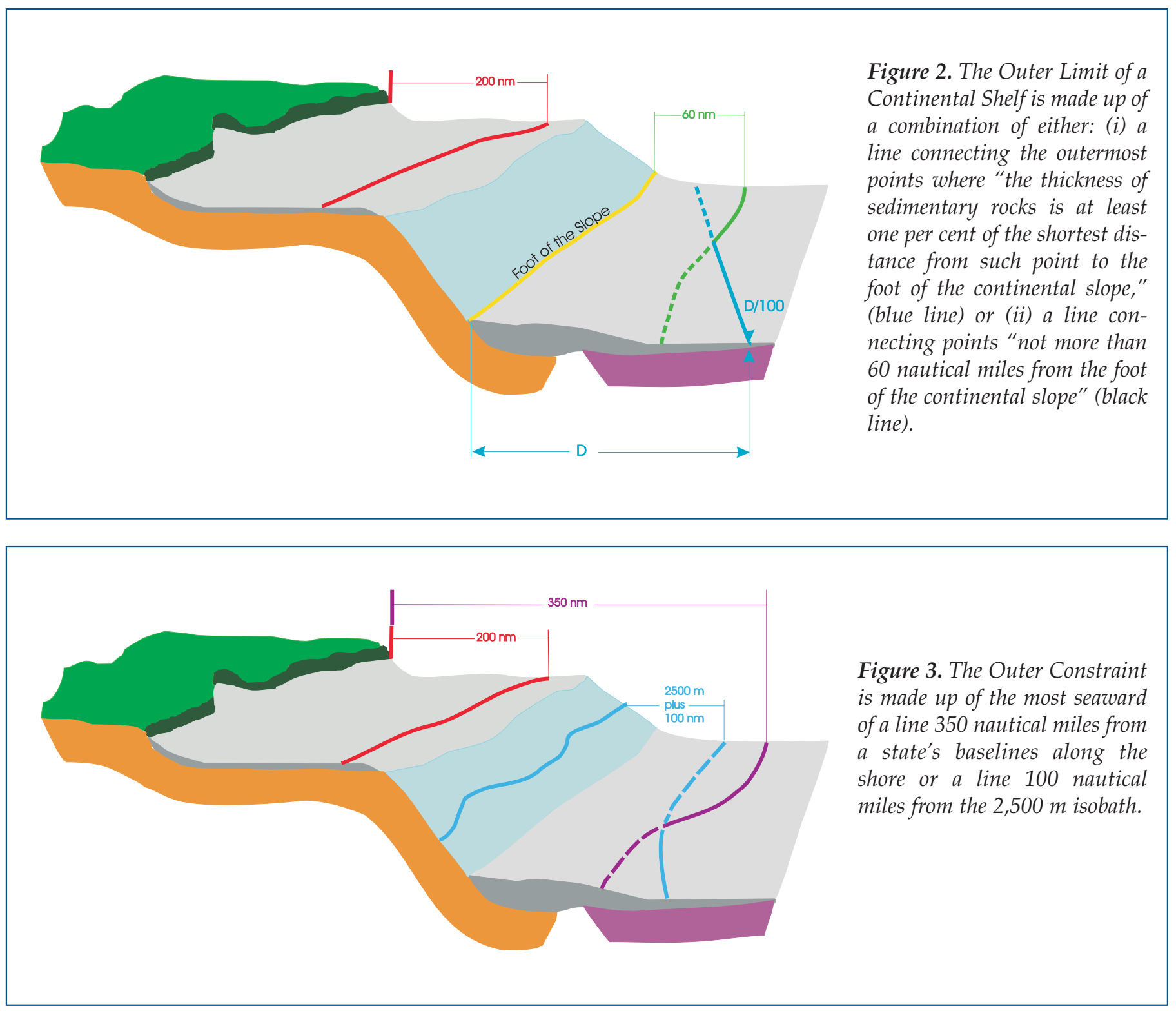

(Johnston, 1988) in a manner that "can be confusing even to experts in the individual fields" (Symonds et al., 2000), provides a multi-tiered formula for the determination of the outer limit of the legal or juridical Continental Shelf (the inner edge is the $200 \mathrm{~nm}$ limit to the Exclusive Economic Zone). In brief, the outer limit of a state's Continental Shelf can be made up of a combination of either: (i) a line connecting the outermost points where"the thickness of sedimentary rocks is at least one per cent of the shortest distance from such point to the foot of the continental slope," or (ii) a line connecting points "not more than $60 \mathrm{~nm}$ from the foot of the continental slope" (Figure 2). The outer limit is constrained to lie inside the most seaward of a line $350 \mathrm{~nm}$ from a state's baselines along the shore or a line $100 \mathrm{~nm}$ from the 2,500-m isobath (Figure 3). Exceptionally, over submarine "ridges," a controversial and imperfectly defined term, only the $350 \mathrm{~nm}$ constraint applies.

\section{Article 76 Work To Be Done}

The work required to substantiate delineating a Continental Shelf under Article 76 breaks down into the mapping tasks listed in Table 1 . Table 1 also includes an assessment of the applicability of altimetry to each of the tasks. This paper goes on to describe a test that demonstrated the application of altimetry to the $2500 \mathrm{~m}$ depth contour and to discuss possible applications to the other tasks.

\section{Mapping the $2500 \mathrm{~m}$ Isobath 2500 m Isobath Defined}

Article 76 defines the 2500 isobath as "a line connecting the depth of 2,500 metres," but does not specify the surface that depth is measured from. Worldwide, $2500 \mathrm{~m}$ isobaths fringe continents and islands, and lie on the flanks of mid-ocean ridges. Not all $2500 \mathrm{~m}$ isobaths will have relevance to Article 76 . Those lying closer to shore than $250 \mathrm{~nm}$ will probably not be the basis of the Outer Constraint. Those that do 


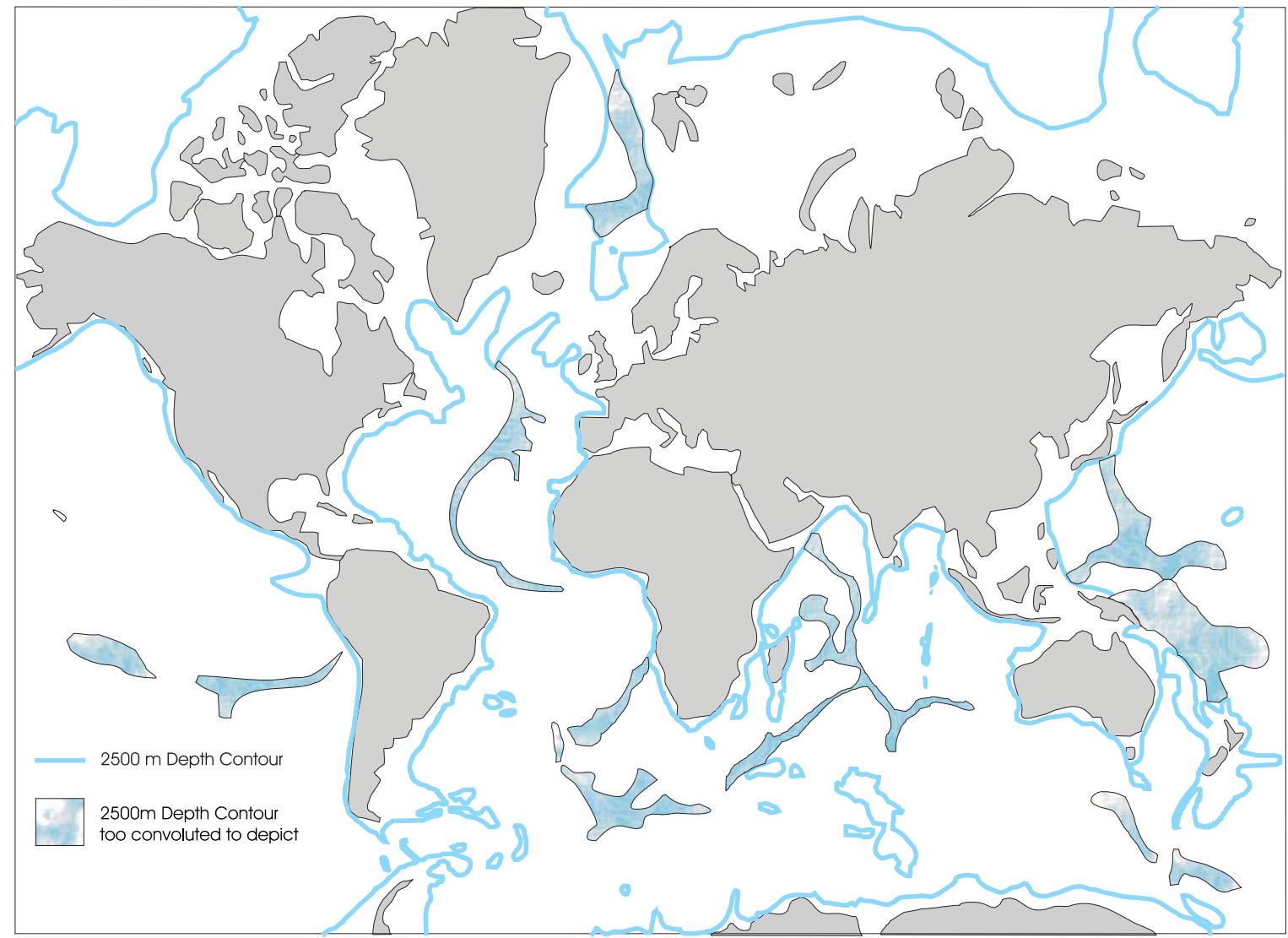

Figure 4. World ocean with $2500 \mathrm{~m}$ isobath shown in blue. Extracted from GEBCO (2003). Note that polar regions are distorted greatly in the Miller projection.

not surround a landmass will be a factor only where they surround an isolated elevation that may be claimed as natural component of a Continental Shelf. Isobaths on the flanks of ridges may be rendered inapplicable by the "Ridges" exception provided in Article 76 Paragraph 6 (discussed below). The $2500 \mathrm{~m}$ isobaths of the world are shown in Figure 4.

The CLCS Guidelines state that for the $2500 \mathrm{~m}$ isobath, the Coastal State must provide an uncertainty assessment based on International Hydrographic Organization Standard S44 (International Hydrographic Organization, 1998). S44 first addresses errors in the measurement of depth through a formula that basically combines the fixed (constant) and variable (i.e., varies with depth) errors as Root Sum of Squares. It specifies, a priori, constant values for the fixed and variable errors that would be acceptable. Applying them at $2500 \mathrm{~m}$ depth yields an allowable error in measuring depths of $\pm 57.5 \mathrm{~m}$. Errors in isobaths produced from the depth measurements are dealt with in S44 as the "Bathymetric Model." Errors are calculated using the same formula as used to determine depth measurement errors, with larger values of the fixed and variable errors. From the S44 tabled values, the allowable error in deriving a $2500 \mathrm{~m}$ isobath from the bathymetry model is $\pm 125 \mathrm{~m}$ (Monahan and Wells, 2002).

The translation of permissible errors in (vertical) depth measurement into horizontal uncertainty of the location of the $2500 \mathrm{~m}$ contour is (Horizontal uncertainty of contour $= \pm$ uncertainty in depth measurement / cosine of bottom gradient) (Monahan and Wells, 1999). Bottom gradients around the $2500 \mathrm{~m}$ contour are generally very low. Pratson and Haxby (1996) measured Continental Slope gradients when they compared both regional and local slopes as measured by Multibeam Echosounder (MBES) over five portions of the US Continental Slope. The steepest area they examined was off New Jersey where they measured a maximum regional slope of 2.5 degrees and a local slope of 7.6 degrees. Monahan and Poll (2002) measured gradient at $2500 \mathrm{~m}$ depth at 920 locations world wide and found that half the world's $2500 \mathrm{~m}$ contour lies on seafloor with gradients less than 2.09 degrees. World wide, the first quartile value was 1.1 degrees and the third equaled 3.83 degrees, while the gradient at $2500 \mathrm{~m}$ off New Jersey was 1.4 degrees.

\section{Test Design and Results}

To test the applicability of predicted bathymetry to 


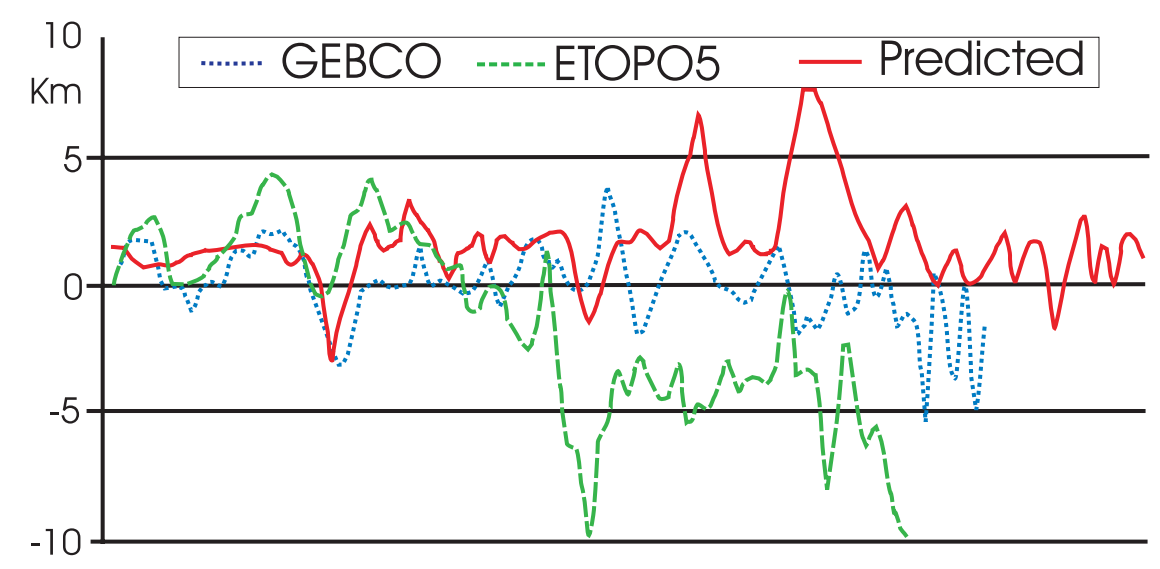

Figure 5. Magnitude of horizontal differences between $2500 \mathrm{~m}$ contours produced from ETOPO5, NOAA Predicted (Altimetric) Bathymetry, GEBCO and a multibeam survey from National Geophysical Data Center Coastal Relief Model. The multibeam is taken as the datum and assigned the value of zero.

locating the $2500 \mathrm{~m}$ isobath, the following test was performed (Monahan and Mayer, 1999). Off New Jersey, USA, the $2500 \mathrm{~m}$ contour produced by data from ETOPO-5 data set, the GEBCO-97 Digital Atlas CD (GEBCO, 1997) and a high-resolution bathymetric data set that included both multibeam and single beam sounder data from the US National Geophysical Data Center's new Coastal Relief Model CDs and the Predicted Topography data set of (Smith and Sandwell, 1997) were compared. Since the multibeam is newest, should be better positioned, internally consistent, suffer little from beamwidth problems, and have no gaps in its coverage of the sea floor, it was considered to be the datum and the horizontal distance between it and the other data sets were measured along a section of the continental slope.

Plotting the four $2500 \mathrm{~m}$ contours together shows that the three ocean-scale data sets interweave each other and form a corridor or confidence zone approximately $10 \mathrm{~km}$ wide. Naturally, these contours contain only long wavelengths. The much shorter wavelengths captured by the multibeam contour weave amongst the other three, and appear to be centered on the zone created by the older three. Assuming the multibeam-derived contour to be true, the horizontal distances from it to the each of the other contours were measured at intervals of $1 \mathrm{~km}$ along a $70-\mathrm{km}$ stretch (Figure 5). The magnitude of these differences is never more than $10 \mathrm{~km}$, and is usually less than $5 \mathrm{~km}$. From a histogram of these differences (Figure 6), it appears that the predicted bathymetry has a systematic horizontal bias of 2-3 km. GEBCO and ETOPO5 do not appear to have a bias, with GEBCO being more closely located to the multibeam contour. Maximum differences between the predicted contour and the MBES contour are less than those between the ETOPO5 contour and the MBES.
If replication of this test in other areas produces similar results, then predicted bathymetry can map the $2500 \mathrm{~m}$ isobath as defined by Article 76 to the accuracy specified by the CLCS Guidelines.

\section{Mapping the Foot of the Slope}

Foot of the Slope and Base of the Slope

Article 76, Paragraph 4(b) states,

"In the absence of evidence to the contrary, the foot of the continental slope shall be determined as the point of maximum change in the gradient at its base."

Most literature written before the issuance of the CLCS Guidelines in 1999 took this to mean that there were two methods of determining the Foot of the Slope, namely by finding the maximum change in gradient or by producing some evidence to the contrary. While the Guidelines essentially agree with these alternatives, they add the step of mapping "... the region defined as the base of the continental slope" within which the Foot of the Slope (as maximum change in gradient) should lie, if it exists at all. In paragraph 5.4.5, the Commission

"...defines the base of the continental slope as a region where the lower part of the slope merges into the top of the continental rise, or into the top of the deep ocean floor where a continental rise does not exist."

On bathymetry maps, whatever their provenance, gradients are steeper where contours are closer together and less steep where contours are further apart, (provided that the contour interval is the same). The Base of the Slope region will in theory lie where the more closely spaced contours of the Slope give way to those wider apart that depict the Rise or the Abyssal 


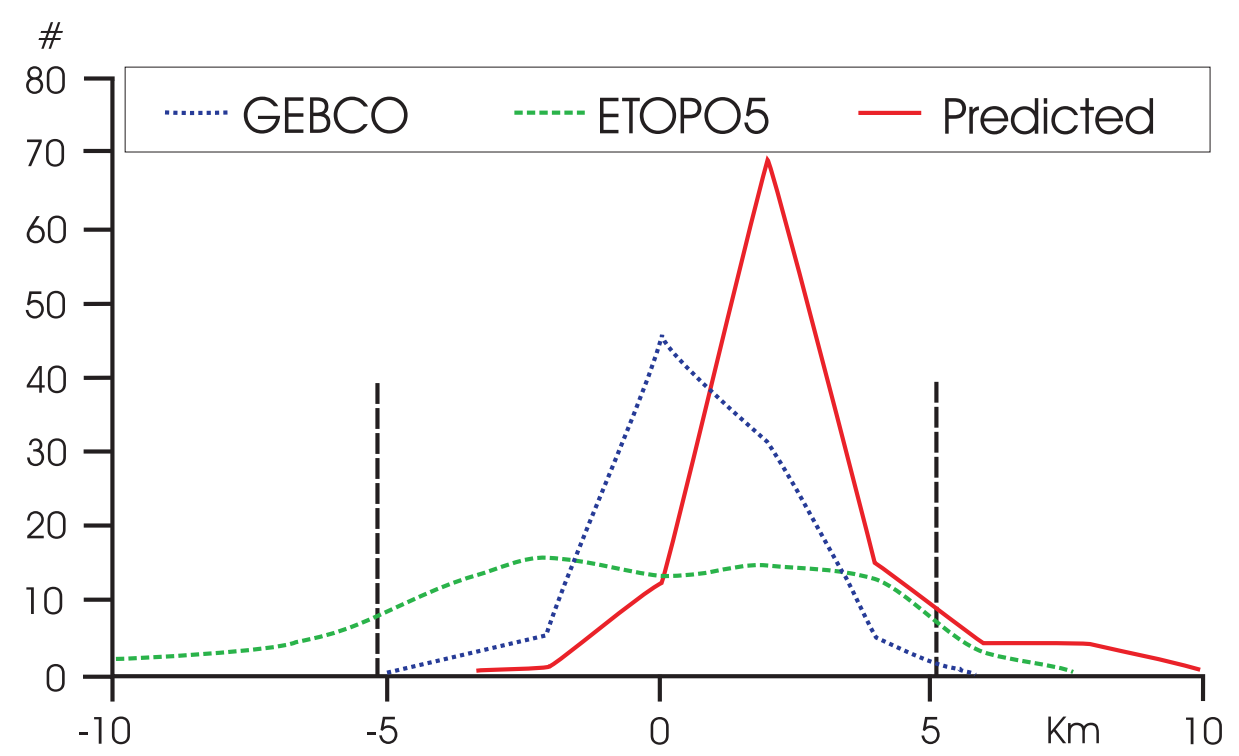

Figure 6. Histogram of horizontal differences between $2500 \mathrm{~m}$ contours produced from ETOPO5, NOAA Predicted (Altimetric) Bathymetry, GEBCO and a multibeam survey from NGDC Coastal Relief Model. The multibeam data are considered as true and the displacement of the other three measured seawards (+) or landward (-). Black vertical lines indicate the permissible horizontal uncertainty under S44 over seafloor sloping 1.4 degrees.

Plain. As shown in Section 2 above, contours derived from altimetry are as accurate as those produced by small scale maps based on acoustic data, and should therefor be as useable for mapping the Base of the Slope as those maps are.

\section{Foot of the Slope as Maximum Change in Gradient}

Within the Base of the Slope region, the Coastal State must map the Foot of the Slope as maximum change of gradient. The location of the Foot of the Slope will vary according to the horizontal range (i.e., scale) over which the gradient is calculated (Monahan, 2003). In general, the smaller the horizontal scale at which a line is mapped, the more convoluted it becomes. It is in the interest of Coastal States seeking to maximize their Continental Shelf to find the most seaward points on the line and use them as the basis of the $60 \mathrm{~nm}$ or sediment thickness lines. Altimetry is not the optimum tool for uncovering small convolutions since they can have a much shorter wavelength than it can detect. On the other hand, it is useful for detecting overall trends that can be used to connect individual points selected from other mapping devices.

\section{Foot of the Slope as Evidence To The Contrary}

There may be circumstances where the Foot of the Slope does not exist or cannot be found as a physiographic feature within the Base region, and in this case, the "evidence to the contrary" clause may be invoked. (Note that the Guidelines state that the CLCS will want to examine the results of the search for Foot of the Slope as maximum change.)

Guidelines Paragraph 6.3.1:

"Evidence to the contrary to the general rule in article 76 , paragraph $4(b)$, is interpreted by the Commission as a provision designed to allow coastal States to use the best geological and geophysical evidence available to them to locate the foot of the continental slope at its base when the geomorphological evidence given by the maximum change in the gradient does not or can not locate reliably the foot of the continental slope."

Evidence to the contrary is not well understood and has not yet been tested. Generally it can be argued that the intent of the framers of UNCLOS was to allow separation of oceanic and continental crusts, which would require geological and geophysical evidence (Haworth, 2003). The extent that altimetry can contribute to that remains to be tested.

\section{Sediment Thickness}

Once the Foot of the Slope has been located, the Outer Limit is based on either a straightforward $60 \mathrm{~nm}$ measurement or a much more involved determination of sediment thickness and sediment continuity. While potential field methods are occasionally used, most commonly this is achieved by seismic profiling, which for UNCLOS purposes will have to be backed up by 
some in situ velocity measurements since absolute thickness is required. Complications arise from correctly identifying of the sediment/basement interface, from calculating sediment thickness and from ensuring its continuity to the $1 \%$ line. There appears to be some level of correlation between sediment thickness and the topography to gravity ratio calculated from altimetry (Smith and Sandwell, 1994, Figures 6 and 7), but it is too early to be able to predict whether this can be converted into an operational tool.

\section{Isolated Elevations and Ridges on the Seafloor}

The simplified model of a continental margin consisting of only a shelf, slope and rise is complicated in places by the presence of two further types of physiographic entities. One of these is isolated elevations, physiographic highs that lie seaward of the main continental slope. The inclusion of such highs within a Coastal State's Continental Shelf can significantly add to its size. To have an elevation accepted as being part of a juridical Continental Shelf, it will have to be shown to be a "natural component" of the margin. The Guidelines describe how elevations can be part of the normal process of accretion on active margins and "thinning, extension and rifting of the continental crust and extensive intrusion of magma" on passive margins. This implies that the evidence to support their inclusion will be primarily geological, to which altimetry can contribute morphological information, particularly about the continuity of the seafloor between the elevation and the continental slope.

Ridges on the seafloor pose a much thornier problem, due to the ambiguous use of the word "ridge" in the Convention. Article 76 Paragraph 6 states

\begin{abstract}
"... on submarine ridges, the outer limit of the continental shelf shall not exceed $350 \mathrm{~nm}$ from the baselines from which the breadth of the territorial sea is measured. This paragraph does not apply to submarine elevations that are natural components of the continental margin, such as its plateaux, rises, caps, banks and spurs."
\end{abstract}

The CLCS points out two uses in UNCLOS of the word "ridge," discusses several methods of ridge formation and concludes (Guidelines 7.2.11),

"As it is difficult to define the details concerning various conditions, the Commission feels it appropriate that the issue of ridges be examined on a caseby-case basis."

Since the term "ridge" is applied in general parlance to features of different geological origin, it is not surprising that confusion can arise when looking at only the wording of Article 76. This can be largely overcome by remembering that the intent of Article 76 is to separate continent from ocean: in gross terms, then, there is no intention to restrict a Coastal State from a ridge that is continental in origin while ridges with an oceanic origin are not to form part of a Continental Shelf. "What seems to be important here is not just that the rock-types of the land mass and the ridge are the same, but that they share the same general crustal characteristics, origin and tectonic setting" (Symonds and Brekke, 2003). Altimetry produces maps of the various ridges that will aid in the interpretation of these three characteristics.

\section{Ancillary UNCLOS Roles for Altimetry}

Existing altimetric bathymetry can clearly be used when conducting a "desk-top study" (Lamont, 1999) of the type used to in the early stages of determining whether a Coastal State has a juridical Continental Shelf that is worth claiming, and for developing a plan of action on the likely area to be included and what data may be needed to substantiate it. Data used at the early planning stages are not necessarily included with that submitted to the CLCS, but the findings from that stage will determine the role of altimetry. Some Coastal States may find that they have sufficient data holdings to allow production of a claim that they can be satisfied with. Others may find that the geometry of their margins is straightforward and an acceptable case can be built without recourse to a great deal of supporting data. More likely, most Coastal States will find that they have a paucity of data and complications in the physiography of their margins that will require detailed interpretation of all existing data and the planning for and collection of a comprehensive and cohesive data set.

During the interpretation of existing data stage, altimetry can be used as a quality-control device to assess the accuracy of the ship sounding data, identifying those that can be used and those that need to be rejected. Once the ship sounding data have been filtered, altimetry can be used to infer morphologic trends between them. This will be particularly useful where the altimetric data identify features between existing sounding lines that have not been detected or whose most seaward extent is unclear. An analysis of this type can do more than reveal areas where further data collection must be undertaken: since altimetry can identify morphological trends, it can help plan the orientation of the new sounding lines.

\section{Summary and Conclusions}

UNCLOS defines zones in the sea in words. Turning the definitions of Territorial Sea, Contiguous Zone and Exclusive Economic Zone into lines on maps and coordinates is reasonably straightforward. On the other hand, delineating the Outer Limit of the juridical Continental Shelf is far from simple, and consists of a number of mapping tasks. Of these, it is presently clear that altimetry can map the $2500 \mathrm{~m}$ depth contour and 
map the "Base of the Slope." It is also possible that altimetry can contribute to mapping the Foot of the Slope, to the evidence to the contrary case, and to resolving the origin of ridges and isolated elevations. Mapping sediment thickness is not yet developed. These will become more open to solution using altimetry data as new instruments allow altimetry to collect data at finer resolution.

Because of its global and uniform data coverage, altimetry is also useful for preliminary studies based on existing data to determine approximate limits to Continental Shelves, help identify gaps in other data sets, and provides quality control of and continuity between widely spaced acoustic sounding lines.

\section{References}

GEBCO, 1997: The 1997 Edition of the GEBCO Digital Atlas, published on behalf of the Intergovernmental Oceanographic Commission (of UNESCO) and the International Hydrographic Organization as part of the General Bathymetric Chart of the Oceans (GEBCO), British Oceanographic Data Centre, Birkenhead, UK., CDROM.

GEBCO, 2003: Centenary Edition of the IHO/IOC General Bathymetric Chart of the Oceans Digital Atlas, Liverpool, UK, published on behalf of the Intergovernmental Oceanographic Commission (of UNESCO) and the International Hydrographic Organization as part of the General Bathymetric Chart of the Oceans (GEBCO) by the British Oceanographic Data Centre, CD-ROM.

Haworth, R.T., 2003: Determination of the Foot of the Continental Slope by Means of Evidence to the Contrary to the General Rule: Conference on Legal and Scientific Aspects of Continental Shelf limits.

International Hydrographic Organization, 1998: Standards for Hydrographic Surveys: Special Publication, 44, International Hydrographic Organization.

Johnston, D.M., 1988: The Theory and History of Ocean Boundary-Making. McGill-Queen's University Press, Montreal, 91 pp.

Lamont, I.: 1999: Formulating the New Zealand continental shelf claim: a first step. In: International conference on Technical Aspects Of Maritime Boundary Delineation and Delimitation, 34-41.

Mayer, L., M. Jakobsson, and A. Armstrong, 2002: The Compilation and Analysis of Data Relevant to a U.S. Claim Under United Nations Law of the Sea Article 76: A Preliminary Report, Durham, N.H., Center for Coastal and Ocean Mapping/Joint Hydrographic Center, University of New Hampshire, 75pp.

Miles, E.L., 1999: The concept of ocean governance: evolution towards the 21st century and the principal of sustainable ocean use. Coastal Management, 27, 1-30.
Monahan, D., 2003: Determination of the Foot of the Continental Slope as the Point of Maximum Change in the Gradient at Its Base. In: Legal and Scientific Aspects of Continental Shelf Limits.

Monahan, D., and L. Mayer, 1999: An examination of publicly available bathymetry data sets using digital mapping tools to determine their applicability to Article 76 of UNCLOS. In: International Conference on Technical Aspects of Maritime Boundary Delineation and Delimitation, 183-190.

Monahan, D., and R.v.d. Poll, 2002: Measured gradients of the sea floor at depths of $2500 \mathrm{~m}$ and their possible influence on the outer limit of juridical Continental Shelves. International Hydrographic Review, 3, 72- 76.

Monahan, D., and D.E. Wells, 1999: Achievable uncertainties in the depiction of the $2500 \mathrm{~m}$ contour and their possible impact on continental shelf delimitation. In: Proceedings, International conference on Technical Aspects Of Maritime Boundary Delineation and Delimitation. International Hydrographic Organization, International Association of Geodesy, Advisory Board on Technical Aspects of Law of the Sea (ABLOS), 261272.

Monahan, D., and D.E. Wells, 2002: The use of the International Hydrographic Organization's "Standards for Hydrographic Surveys" as a measure of depth accuracy in Continental Shelf determinations. International Hydrographic Review, 3(1), 5967.

Murton, B., L. Parson, P. Hunter, and P. Miles, 2000: Global non-living resources on the extended continental shelf: prospects at the year 2000. International Seabed Authority, Kingston, Jamaica, $64 \mathrm{pp}$.

Pratson, L.F., and W.F. Haxby, 1996: What is the slope of the U.S. continental slope? Geology, 24, 3-6.

Smith, W.H.F., and D.T. Sandwell, 1997: Global sea floor topography from satellite altimetry and ship depth soundings. Science, 277, 1956-1962.

Symonds, P., and H. Brekke, 2003: A scientific overview of ridges related to Article 76 of the UN Convention on the law of the sea. In: Legal and Scientific Aspects of Continental Shelf Limits.

Symonds, P., O. Eldholm, J. Mascle, and G. Moore, 2000: Characteristics of continental margin: Continental Shelf Limits. In: The Scientific and Legal Interface, P.J. Cook, and C.M. Carleton, eds., Oxford University Press, 25-63.

United Nations, 1983: The Law of the Sea: United Nations Convention on the Law of the Sea, with Index and Final Act of the Third United Nations Convention on the Law of the Sea, UN Publication Sales No. E.93., V.16.

United Nations, 1999: Scientific And Technical Guidelines Of The Commission On The Limits Of The Continental Shelf, CLCS11, United Nations, 91 p. 